\title{
Development of Modified Caprylic Acid Fractionation Method for the Enhanced Yield and Purity of Equine Polyvalent Antisnake Venom Immunoglobulins
}

\author{
Sunil Kumar Arora1, Partha Rakshit ${ }^{2}$, Dilip Singh Rawat ${ }^{1}$ and Ravi Kumar Gupta ${ }^{1 *}$ \\ ${ }^{1}$ Central Research Institute, Kasauli, Himachal Pradesh, India \\ ${ }^{2}$ National Centre for Disease Control (NCDC), New Delhi
}

\begin{abstract}
Polyvalent antivenom IgG s produced in equines against different snake venom are used for treatment in snakebite cases. For this, hyperimmune equine plasma is fractionated and purified before use. Hence, serum related side effects are common. To reduce it, search for more effective method with high yield and purity, is of concern. In the present study, a modified caprylic acid method for the fractionation of $\mathrm{IgG}$, has been described. The method was also compared with routine method and previously described caprylic acid methods. The results indicated that modified caprylic acid method at concentration 1.5\%, $\mathrm{pH} 4.8$ with stirring for 60 minutes, was superior in terms of yield, and purity as compared to other methods $(\mathrm{p}<0.05)$. The purified lgG were also found to have better neutralizing potency against all the four venoms viz., Cobra (Naja naja), Krait (Bungarus caeruleus), Russell's viper (Vipra russelli), and Saw Scaled viper (Echis carinatus). The results suggest that modified caprylic acid method, could be of great value for commercial scale production of antivenom with respect to its efficacy, simplicity, low cost, reduced production time and above all high yield of colorless IgG finished product.
\end{abstract}

Keywords: Antisnake venom serum; Hyperimmune plasma; Caprylic acid; Efficacy; Efficiency

\section{Introduction}

Antisnake venom serum (ASVS) obtained from hyper immune equine plasma has long been used for the treatment of life threatening snakebite cases [1]. However, for the production of a safe and potent ASVS, several methods of antiserum purification such as ammonium sulfate precipitation [2,3], affinity and ion exchange chromatography [4,5] caprylic acid precipitation [6], ethanol precipitation [7], PEG precipitation [8], and salt precipitation [9] have been reported. Despite of availability of wide range of purification strategies, ammonium sulfate precipitation method is most commonly used for the commercial production of ASVS. In routine, the use of ASVS is associated with adverse reactions due to contaminating proteins. Despite that, it needs to be used during life threatening snake bite cases. It is generally understood that more "Refined" the antivenom, the less likely would be the chances of anaphylactic and adverse reactions following its use [1012]. Therefore, to avoid use related allergic reactions, the production of highly purified ASVS is need of hour [13].

Various studies have been carried out to develop production procedures for the purification and concentration of ASVS so as to obtain highly purified ASVS. The routinely used method for the purification of plasma is ammonium sulphate precipitation, with or without pepsin digestion. It results in a product containing mixture of $\mathrm{F}(\mathrm{ab}) 2$ and un-cleaved IgG [2,3]. This mixture result in number of ASVS complications such as use related allergic reactions, less stability, low yield and protein aggregates on storage. Therefore, for commercial production of ASVS, there is a need to develop a method that not only provide satisfactory yield and purity of product but should also be economical and less complicated. Central Research Institute, Kasauli is a major producer of ASVS in India. This institute is producing ASVS from almost a century. In the present study, an attempt was made to develop and validate a method for the fractionation and isolation of polyvalent IgG from hyperimmune equine plasma using caprylic acid. Although, caprylic acid has been reported to yield higher specific activity and yield, economical and simple procedure for the fractionation of hyperimmune plasma [14-17] but in the present study, caprylic acid conditions has been optimized and vaildated at different parameters both at laboratory and large scale production. The routinely used ammonium sulphate precipitation method was used as control to find out its suitability for its use in commercial production of ASVS.

\section{Materials and Methods}

\section{Venom samples}

Lyophilized whole venoms of four common Indian poisonous snakes viz., Cobra (Naja naja) [CV], Krait (Bungarus caeruleus) $[\mathrm{KV}]$, Russell's viper (Vipera russelli) $[\mathrm{RV}]$ and Saw scaled viper (Echis carinatus) $[\mathrm{EV}]$ were procured from "The Irula Snake Catcher's Industrial Co-operative Society" Chennai (India) and "Haffkines Biopharmaceutical Corporation Ltd.," Mumbai (India). To cover wider antigenicity for hyper immunization, the venoms of each snake species obtained from different regions were pooled in equal quantities (w/w) and stored at $-20^{\circ} \mathrm{C}$. All other chemicals and reagents used were of analytical grades.

\section{Equines and immunization schedule}

Large sized Indian bred equines i.e., both horses (weight $\geq 400 \mathrm{Kg}$ ) and mules (weight $\geq 250 \mathrm{Kg}$ ) aged 6-17 years were used in study. For the production of polyvalent antivenom serum, equines were immunized

*Corresponding author: Ravi Kumar G, Central Research Institute, Kasauli-173 204, Himachal Pradesh, India, Tel: +911792273118; E-mail: rkgupta08@gmail.com

Received October 31, 2016; Accepted November 18, 2016; Published November 21, 2016

Citation: Sunil Kumar A, Rakshit P, Dilip Singh R, Ravi Kumar G (2016) Development of Modified Caprylic Acid Fractionation Method for the Enhanced Yield and Purity of Equine Polyvalent Antisnake Venom Immunoglobulins. Bioprocess Biotech 6: 288. doi:10.4172/2155-9821.1000288

Copyright: (C) 2016 Sunil Kumar A, et al. This is an open-access article distributed under the terms of the Creative Commons Attribution License, which permits unrestricted use, distribution, and reproduction in any medium, provided the original author and source are credited. 
Page 2 of 6

\begin{tabular}{|c|c|c|c|c|c|c|}
\hline \multirow{2}{*}{ Days } & \multicolumn{4}{|c|}{ Venom dose (mg) } & \multirow{2}{*}{ Volume injected (ml) } & \multirow{2}{*}{ Route of injection } \\
\hline & CV & KV & RV & EV & & \\
\hline 0 & 0.10 & 0.01 & 0.10 & 0.01 & 2.0 & \multirow{10}{*}{ Deep intramuscular } \\
\hline 15 & 0.20 & 0.02 & 0.20 & 0.02 & 2.0 & \\
\hline 30 & 0.30 & 0.03 & 0.30 & 0.03 & 2.0 & \\
\hline 45 & 0.40 & 0.04 & 0.40 & 0.04 & 2.0 & \\
\hline 60 & 0.50 & 0.05 & 0.50 & 0.05 & 2.0 & \\
\hline 75 & 0.60 & 0.06 & 0.60 & 0.06 & 2.0 & \\
\hline 90 & 0.70 & 0.07 & 0.70 & 0.07 & 2.0 & \\
\hline 105 & 0.80 & 0.08 & 0.80 & 0.08 & 2.0 & \\
\hline 120 & 0.90 & 0.09 & 0.90 & 0.09 & 2.0 & \\
\hline 135 & 1.00 & 0.10 & 1.00 & 0.10 & 2.0 & \\
\hline
\end{tabular}

Table 1: Schedule of immunization of equines for the production of polyvalent antisnake venom serum.

intramuscularly with sterile liquid preparation of four common Indian snake species venom homogenized with Freund's incomplete adjuvant (Table 1) [18,19]. After completion of immunization schedule, equines were test bled and plasma was separated by using tri-Sodium citrate $(0.05 \% \mathrm{w} / \mathrm{v})$ as anticoagulant. The plasma was separated by centrifugation $(2000 \mathrm{~g} \times 15 \mathrm{~min})$. Phenol was added as preservative $(0.2 \% \mathrm{w} / \mathrm{v})$ and was stored at $2-8^{\circ} \mathrm{C}$.

\section{Standardization of caprylic acid fractionation method}

To determine the optimum conditions for IgG fractionation by using caprylic acid, 3 key variables as concentration, $\mathrm{pH}$ and stirring time were standardized initially at pilot scale.

Caprylic acid concentration: Small lots of hyper immune equine plasma were diluted with water for injection (WFI) to get $2 \mathrm{~g}$ percent protein concentration and these samples were digested with pepsin $\left(0.1 \% \mathrm{w} / \mathrm{v}\right.$, Himedia) at $\mathrm{pH} 3.2$ at $30^{\circ} \mathrm{C}$ for one hour. After digestion, caprylic acid (Merck, Germany) was added to the reaction mixture in different concentrations viz. 1.0, 1.5, 2.0, 2.5, 3.0, 3.5, 4.0 and 5.0\% (v/v). Mixture was agitated vigorously for 60 minutes at $22-24^{\circ} \mathrm{C}$. The aliquots were filtered through Whatman filter paper (No.1) and the filtrates were dialyzed against distilled water to remove caprylic acid. The IgG preparations obtained were concentrated by diafiltration to approximately $3-4 \mathrm{~g}$ protein concentration. The $\mathrm{pH}$ was adjusted to 6.8 . The caprylic acid concentration giving the best result in neutralizing assay was selected for further experiments.

pH: Pepsin digested aliquots of plasma were prepared and their $\mathrm{pH}$ was adjusted to $4.0,4.5,4.8,5.0,5.4,5.8$ and 6.0 with $2 \mathrm{~N} \mathrm{NaOH}$. The caprylic acid was added slowly to give final optimal concentration, and the plasma was fractionated as described above. The $\mathrm{pH}$ giving the best result in neutralizing assay was selected for further experiments.

Stirring time: As worked above, the optimal caprylic acid concentration and $\mathrm{pH}$ was obtained in pepsin digested aliquots of plasma. The samples were agitated vigorously for different time periods viz., 30, 60 and $90 \mathrm{~min}$. The plasma proteins were fractionated as described above and the time giving the best result in neutralizing assay was selected for further experiments.

\section{Purification of plasma by caprylic acid and ammonium sulfate fractionation}

Caprylic acid fractionation: Plasma batches were diluted with WFI to get $2 \mathrm{~g}$ percent protein concentration. The diluted plasma samples were digested with pepsin $(0.1 \% \mathrm{w} / \mathrm{v}, \mathrm{pH} 3.2)$ at $30^{\circ} \mathrm{C}$ for one hour. The caprylic acid was added slowly with stirring in a final concentration previously optimized. The samples were stirred at standardized agitation speed for one hour at $22-24^{\circ} \mathrm{C}$. Treated plasma was filtered through Whatman filter paper (No.1). The filtrates were dialyzed against distilled water to remove caprylic acid and concentrated to 3-4 g percent protein. The lgG preparations thus obtained were filtered again and the $\mathrm{pH}$ was adjusted to 6.8 .

Ammonium sulfate fractionation: As control, routinely used ammonium sulphate fractionation method was used [20]. Briefly, plasma was diluted with WFI to obtain $2 \%$ protein concentration and pepsin treatment was given. The specific gravity of the mixture was adjusted to 1.090 with ammonium sulfate and the $\mathrm{pH}$ was adjusted to 4.8 at room temperature. The temperature of the mixture was then raised to $56^{\circ} \mathrm{C}$ for 30 minutes with continuous stirring followed by immediate cooling to $22^{\circ} \mathrm{C}$. After filtration, the specific gravity of filtrate was increased to 1.160 by adding more ammonium sulfate with constant stirring and the $\mathrm{pH}$ was raised to 5.5. The $\lg \mathrm{G}$ precipitate was collected by filtration, dissolved in WFI and dialyzed.

Reference methods control: Two more methods for plasma fractionation for IgG purification as described by Rojas et al. [6] and Dos Santos et al. [21] were used as reference control. Briefly, in Rojas et al. [6] method, the $\mathrm{pH}$ of undiluted plasma was adjusted to 5.8 with $1.76 \mathrm{~N}$ acetic acid and caprylic acid was added to a final concentration of $5 \%$ with vigorous stirring for one hour. The mixture was filtered and dialyzed as described above. According to Dos Santos et al. [21] the hyper immune plasma was diluted to $40 \mathrm{mg} / \mathrm{ml}$ protein concentration and pepsin treatment was given. The $\mathrm{pH}$ of reaction mixture was adjusted to 5.0 and caprylic acid was added with vigorous stirring to the final concentration of $8.7 \%$. IgG fraction was isolated, dialyzed and preserved as described above.

\section{Determination of antivenom neutralizing potency}

In-vivo potency assay of plasma (unprocessed) and purified plasma were carried out by neutralization assay in Swiss Albino mice (17-20 g). Ethical clearance was granted by Institution Animal Ethics Committee. For potency estimation, graded venom concentrations of venoms were prepared in sterile normal saline in $0.02 \mathrm{mg}$ increments and were added to test tubes. Final volume was made $1.0 \mathrm{ml}$ with normal saline. To each tube, $1.0 \mathrm{ml}$ of unprocessed and purified plasma was added and the tubes were incubated at $37^{\circ} \mathrm{C}$ for 30 minutes. The positive and negative venom control mixtures were also prepared as described above. $0.5 \mathrm{ml}$ of each dilution of the mixture was injected intravenously to group of mice (6 mice/group). Deaths of mice were observed at 48 hours intervals after the injection. The protective potency was taken as the highest venom concentration where all the mice in a group survived.

\section{Abnormal toxicity test}

Five Swiss albino mice (17-20 g weight) and two Guinea pigs (250$350 \mathrm{~g}$ ) were injected respectively with $1 \mathrm{ml}$ and $5 \mathrm{ml}$ of plasma samples 


\begin{tabular}{|c|c|c|c|c|}
\hline \multirow{2}{*}{$\begin{array}{c}\text { Caprylic acid } \\
\text { Concentration \% (v/v) }\end{array}$} & \multicolumn{4}{|c|}{ Neutralizing Potency (mg/ml) } \\
\hline 0.5 & CV & KV & RV & EV \\
\hline 1.0 & $0.60 \pm 0.02$ & $0.62 \pm 0.01$ & $0.58 \pm 0.01$ & $1.80 \pm 0.14$ \\
\hline 1.5 & $0.70 \pm 0.01$ & $0.72 \pm 0.02$ & $0.65 \pm 0.02$ & $2.0 \pm 0.02$ \\
\hline 2.0 & $0.76 \pm$ & $0.76 \pm$ & $0.66 \pm 0.01^{*}$ & $2.30 \pm 0.16^{*}$ \\
\hline 2.5 & $0.01^{*}$ & $0.01^{*}$ & & \\
\hline 3.0 & $0.70 \pm 0.02$ & $0.72 \pm 0.01$ & $0.62 \pm 0.01$ & $2.20 \pm 0.16$ \\
\hline 3.5 & $0.70 \pm 0.01$ & $0.70 \pm 0.02$ & $0.60 \pm 0.01$ & $2.00 \pm 0.08$ \\
\hline 4.0 & $0.65 \pm 0.02$ & $0.65 \pm 0.01$ & $0.65 \pm 0.02$ & $1.70 \pm 0.08$ \\
\hline 5.0 & $0.60 \pm 0.01$ & $0.66 \pm 0.01$ & $0.60 \pm 0.01$ & $1.60 \pm 0.16$ \\
\hline $0.56 \pm 0.02$ & $0.52 \pm 0.02$ & $0.56 \pm 0.02$ & $1.50 \pm 0.16$ \\
\hline & $0.50 \pm 0.01$ & $0.50 \pm 0.01$ & $0.52 \pm 0.01$ & $1.40 \pm 0.16$ \\
\hline
\end{tabular}

Table 2: Effect of Caprylic acid concentration on fractionation of hyperimmune equine plasma for polyvalent antivenom IgG. The neutralization is expressed in $\mathrm{mg}$ venom neutralized per $\mathrm{mL}$ of antivenom. The results are expressed as mean value \pm S.D. ${ }^{*} p<0.01$.

\begin{tabular}{|c|c|c|c|c|}
\hline \multirow{2}{*}{$\mathbf{p H}$} & \multicolumn{4}{|c|}{ Neutralizing Potency (mg/ml ) } \\
\cline { 2 - 5 } & $\mathbf{C V}$ & $\mathbf{K V}$ & $\mathbf{R V}$ & EV \\
\hline 4.0 & $0.70 \pm 0.02$ & $0.70 \pm 0.01$ & $0.60 \pm 0.01$ & $2.10 \pm 0.11$ \\
\hline 4.5 & $0.76 \pm 0.01$ & $0.76 \pm 0.01$ & $0.66 \pm 0.01$ & $2.30 \pm 0.16$ \\
\hline 4.8 & $0.82 \pm 0.05^{\star}$ & $0.82 \pm 0.08^{*}$ & $0.76 \pm 0.16^{*}$ & $2.40 \pm 0.08^{*}$ \\
\hline 5.0 & $0.76 \pm 0.01$ & $0.72 \pm 0.02$ & $0.60 \pm 0.05$ & $2.00 \pm 0.08$ \\
\hline 5.4 & $0.74 \pm 0.05$ & $0.72 \pm 0.02$ & $0.58 \pm 0.05$ & $1.90 \pm 0.08$ \\
\hline 5.8 & $0.72 \pm 0.02$ & $0.70 \pm 0.01$ & $0.55 \pm 0.01$ & $1.90 \pm 0.08$ \\
\hline 6.0 & $0.66 \pm 0.01$ & $0.66 \pm 0.01$ & $0.50 \pm 0.01$ & $1.90 \pm 0.11$ \\
\hline
\end{tabular}

Table 3: Effect of $\mathrm{pH}$ on the fractionation of hyperimmune plasma with caprylic acid $(1.5 \% \mathrm{w} / \mathrm{v})$ for polyvalent antivenom IgG production. The neutralization is expressed in $\mathrm{mg}$ venom neutralized per $\mathrm{mL}$ of antivenom. The results are expressed as mean value \pm S.D. ${ }^{*} p<0.01$

\begin{tabular}{|c|c|c|c|c|}
\hline \multirow{2}{*}{ Stirring time (Minutes) } & \multicolumn{4}{|c|}{ Potency (mg/ml) } \\
\cline { 2 - 5 } & CV & KV & RV & EV \\
\hline 30 & $0.72 \pm 0.02$ & $0.74 \pm 0.02$ & $0.60 \pm 0.01$ & $2.10 \pm 0.08$ \\
\hline 60 & $0.82 \pm 0.01^{*}$ & $0.86 \pm 0.02^{*}$ & $0.74 \pm 0.01^{*}$ & $2.50 \pm 0.08^{*}$ \\
\hline 90 & $0.80 \pm 0.02$ & $0.85 \pm 0.03$ & $0.71 \pm 0.02$ & $2.51 \pm 0.11$ \\
\hline
\end{tabular}

Table 4: Effect of stirring time on the caprylic acid fractionation of equine plasma for polyvalent antivenom IgG production. The neutralization is expressed in $\mathrm{mg}$ venom neutralized per $\mathrm{mL}$ of antivenom. The results are expressed as mean value \pm S.D. ${ }^{*} p<0.01$.

intraperitoneally and were observed for 7 days for any abnormal symptom or loss in body weight [20].

\section{Aggregation of proteins on storage}

3 aliquots of sterile purified serum in $10 \mathrm{ml}$ volume were incubated undisturbed at $2-8^{\circ} \mathrm{C}$ and $35^{\circ} \mathrm{C}$. Observations were made on day 15 and 30 for visible turbidity or protein aggregation by visual method and microscopy.

\section{Protein and albumin concentrations}

Total protein was estimated by standard Biuret method and albumin was determined by the standard modified Bromocresol green method as described by Schosinsky et al. [22].

\section{Immunoelectrophoresis of antivenom}

Immunoelectrophoresis of purified samples was carried out in $1.2 \%$ agarose gel using barbitone buffer at $\mathrm{pH} 8.6$ [22]. The wells were marked and four venom solutions were added individually and the antivenom was added to the troughs. The gels were electrophoresed for 3 hours at $300 \mathrm{~V}, 30 \mathrm{~mA}$ current. The gels were stained with amido black dye, washed, and dried in an incubator at $35^{\circ} \mathrm{C}$.

\section{Statistical analysis}

All experiments were carried out in duplicate to validate the reproducibility of the experiments. Results were assessed by ANOVA, and post hoc test (Tukey) was applied, wherever applicable. Differences were considered statistically significant when $\mathrm{p}<0.05$.

\section{Results and Discussion}

The identity and purity of an immunobiological is an integral component of pharmacopeia requirement. Snake venom is heterogeneous in composition and multiplicity of effects evoked by some venom components are due to their simultaneous toxic or lethal effects on blood, cardiovascular, respiratory and nervous system [23] Venoms are the most complex mixtures of both proteinaceous and nonproteinaceous components, which include proteolysins and histolysin; cardio toxin; haematocytolysins; lecithinase, thrombinogen and anticytozymes; neurocytolysins etc. [23,24]. The antigenic composition of venoms is different and is characteristic of the particular snake species. Even the same snake's species existing in different geographical regions has been reported to have different venom antigenic composition due to climatic and geographical variations [25]. The venoms, when injected into the animal body in tolerable, preferably less toxic and gradual increasing doses, repeatedly at an appropriate interval of time, elicits the formation and concentration of antibodies in their plasma. This hyperimmune plasma is the substrate material for antisera production industry. Despite the fact of multiple serum associated unwanted allergic reactions, serum therapy is the treatment of choice, and is clinically efficient in snakebite cases. In order to overcome these side effects, several methods for plasma fractionation have been tried over the years to obtain a product of high purity with reduced/ no allergic reactions $[2,4,7,8]$. However, the exact mechanism of adverse reactions to antivenom is uncertain. It may occur due to type I hypersensitivity reactions, but reactions usually occur in person with history of equine serum use. It has been hypothesized that combination of type I hypersensitivity, complement activation and the effect of aggregates of immunoglobulin or immunoglobulin fragments, may cause the early reactions [26]. Further, manufacturing process also appears to influence reaction rates [27]. As the proteins present in equine heterologous serum have immunogenic properties; therefore, anaphylaxis reactions may appear in subsequent exposure to the similar therapy. The serum sickness reactions usually appear 5 to 24 days after the use of heterologous serum and are manifested by fever, urticaria, arthalgia, lymphadenopathy, proteinuria and peripheral neuropathy. Further, deposition of $\lg G$ and $\operatorname{lgM}$ antibodies immune-complexes in several tissues causes acute inflammatory responses also [28,29]. Therefore, production of safe and pure heterologous equine serum or its substitute (homologous serum) is recommended to eliminate the risk of hypersensitivity reactions [13].

In the present study, first of all caprylic acid concentration, $\mathrm{pH}$, and stirring time was standardized. For concentration, hyperimmune plasma was fractionated with different concentration of caprylic acid and potency of the product was assessed through neutralization assay (Table 2). Caprylic acid at concentration of $1.5 \%$ showed the statistically significant potency results as compared to others $(\mathrm{p}<0.01)$. A decrease in potency was observed at concentration lower or more than $1.5 \%$. Table 3 shows the effect of $\mathrm{pH}$ on neutralization capacity of IgG obtained from pepsin digested plasma at $1.5 \%$ caprylic acid concentration. Maximum neutralization was obtained at $\mathrm{pH} 4.8$ while statistically significant low yield of IgG was observed at $\mathrm{pH}$ less or more than $4.8(\mathrm{p}<0.01)$. The stirring of plasma play a very important role in completion of the precipitation process. At optimized concentration of caprylic acid and $\mathrm{pH}$, the effect of stirring time was also studied. 


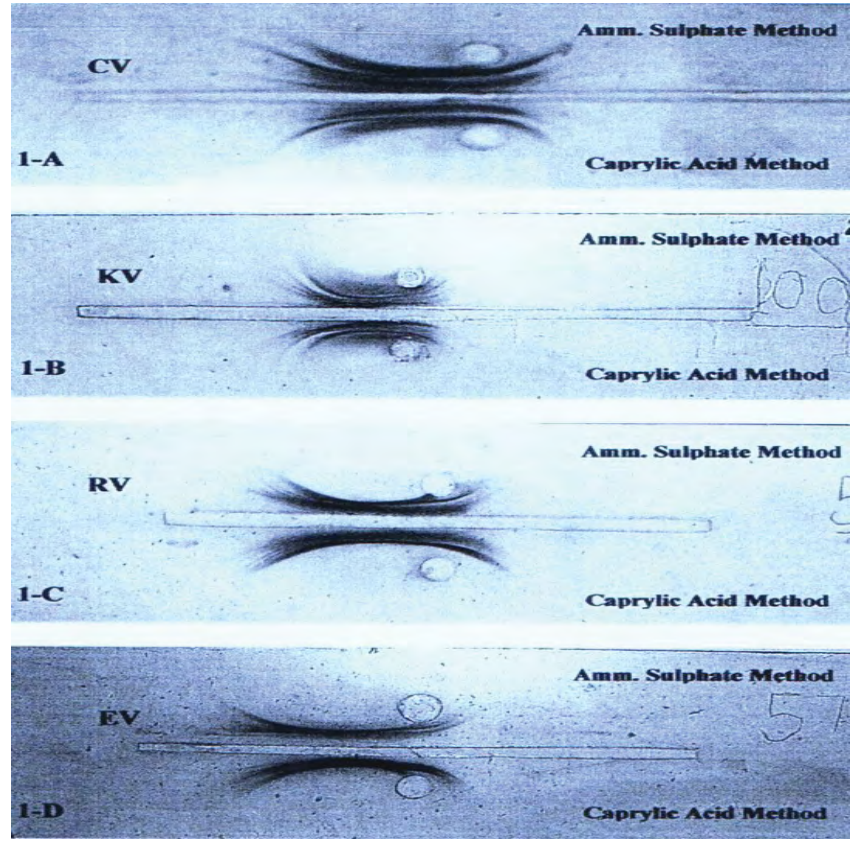

Figure 1: Electrophoretic patterns of antisnake venom immunoglobulins purified by Ammonium sulphate and Caprylic acid fractionation methods against Cobra (1-A); Krait (1-B); Russell's Viper (1-C) and Saw scaled viper (1-D). For immunoelectophoresis, the venoms were separated by electrophoresis followed by placing antivenom in the troughs, and was allowed to diffuse and immunoreact with the specific venom components separated in the gel. The gels were stained with amido black after electrophoresis.

The results indicated that stirring time for one hour after caprylic acid addition gives statistically significant best quality IgG preparation as observed by potency results (Table 4$) \mathrm{p}<0.01$ ). Therefore, caprylic acid concentration (1.5\%), $\mathrm{pH} 4.8$, and one hour stirring time were chosen as the optimal conditions for the further experiments.

With the advancement of technology, currently antisera are purified by enzyme digestion, chemicals precipitation, and thermo coagulation to remove excessive animal proteins. The combinations of these processes yield serum with low contaminating proteins, and hence, making it more safe and efficient along with reduced incidence of hypersensitivity reactions [30,31]. In the present study, IgG fractionation using hyper immune polyvalent equine plasma was carried out using modified caprylic acid method and other conventional methods. Under specific physicochemical conditions, caprylic acid has been reported to precipitate non IgG serum proteins leaving highly enriched IgG preparation in the solution $[14,17,31]$. Before fractionation, the diluted plasma was digested with pepsin to obtain antivenom $\mathrm{F}(\mathrm{ab}$ ') fragments. Initially, the experimental conditions for the use of caprylic acid were optimized on pilot scale and later its advantage was demonstrated on larger batch sizes over the routinely used ammonium sulfate fractionation method. It has been recommended that before adapting a new method for commercial production, same should be optimized initially on multiple parameters. Once after optimization, same should be scaled up to large volume size batches and the results obtained should be compared and validated to small volume size batches used for optimization.

In the present study, equine plasma was diluted prior to fractionation. It has been observed that diluted plasma yield more than that of concentrated plasma [6]. During optimization studies, the addition of caprylic acid at $1.5 \%$ concentration at $\mathrm{pH} 4.8$ with stirring for one hour yielded the pure product with high neutralization capacity. Therefore, fractionation was carried out at $1.5 \%$ caprylic acid concentration at $\mathrm{pH}$ 4.8 with vigorous stirring for 1 hour. However, the results were contrary to findings of other workers using caprylic acid where $\mathrm{pH} 5.0$ and 5.8 were used to fractionate undiluted equine plasma, respectively $[6,21]$. After initial optimization, the quality of plasma produced was assessed on the basis of key variables such as total heterologous proteins content, residual albumin content, and protein aggregate formation on storage, turbidity, color, final yield, electrophoretic pattern, and abnormal toxicity in vivo.

To evaluate the efficiency of modified caprylic acid method, multiple bulk batches of hyper immune plasma were fractionated by modified caprylic acid, routinely used ammonium sulfate fractionation method, and previously described caprylic acid methods of Dos Santos et al. [21] and Rojas et al. [6]. The results of multiple batches fractionation obtained from different methods were compared for immunogenic and physiochemical characteristics (Table 5). The results showed significantly low potency of antisera fractionated by the caprylic acid methods of Dos Santos et al. [21] and Rojas et al. [6] as compared to routinely used ammonium sulfate and modified caprylic acid methods $(\mathrm{p}<0.001)$. The previously described caprylic acid methods were also found to give moderate to high levels of protein aggregate formation on storage. However, the yield and purity of IgG preparation obtained by modified caprylic acid fractionation method was significantly higher as compared to all other three methods $(\mathrm{p}<0.001)$. The results of modified caprylic acid method also showed significantly lower level of albumin content as compared to other methods, indicating the high purity in terms of high IgG content $(\mathrm{p}<0.001)$. It indicates more $\mathrm{F}\left(\mathrm{ab} \mathrm{b}^{\prime}\right)$ antibody fraction and less foreign protein load, and hence, colorless product in contrast to yellowish tinged produced with other methods (Table 5). The results were found to be statistically significant when results of modified caprylic acid method were compared with other caprylic acid method by employing ANOVA followed by post hoc "Tukey" ( $\mathrm{p}<0.001)$

The results of modified caprylic acid method were compared statistically with the routinely used ammonium sulfate fractionation method and earlier reported caprylic acid methods of Rojas et al. [6] and Dos Santos et al. [21]. A significant difference in potency, yield, protein value and albumin content $(\mathrm{p}<0.01)$ was observed among the modified caprylic acid and earlier described methods [6,21]. Further, the plasma fractionated by Rojas et al. [6] and Dos Santos et al. [21] methods yielded antivenom of significant low potency, low yield and with higher albumin contents compared to routinely used ammonium sulfate fractionation method. The results of present study suggest that the modified caprylic acid method was superior, specifically in terms of yielding pure $\mathrm{F}\left(\mathrm{ab}^{\prime}\right)$ antibody fraction. These results are in corroboration with the other findings where caprylic acid has been used under different set of conditions and have been concluded as economical, simple method to yield high purity and specific antisera $[14,16,17]$. It also reduces foreign protein load and colorless product in contrast to yellowish tinged produced with other methods indicating less side effects on use.

$\mathrm{F}\left(\mathrm{ab}^{\prime}\right)$ fragments of IgG obtained after purification with modified caprylic acid method and routinely employed ammonium sulfate fractionation method, were mapped electrophoretically (Figure 1). The Ab:Ag reaction band pattern obtained with purified sera of two methods confirmed identity, recovery and similarity among all the antibody fractions elicited by different antigenic fractions of all the four Indian snake species. It indicates that modified caprylic acid method was equally good and comparable to routinely used ammonium 


\begin{tabular}{|c|c|c|c|c|c|}
\hline \multirow{2}{*}{\multicolumn{2}{|c|}{ Parameter }} & \multirow{3}{*}{$\begin{array}{c}\begin{array}{c}\text { Modified Caprylic acid } \\
\text { method }\end{array} \\
0.84 \pm 0.02^{*}\end{array}$} & \multirow{3}{*}{$\begin{array}{c}\begin{array}{c}\text { Ammonium sulfate } \\
\text { fractionation }\end{array} \\
0.82 \pm 0.05\end{array}$} & \multicolumn{2}{|c|}{ Previously known Caprylic acid methods } \\
\hline & & & & \multirow{2}{*}{$\begin{array}{l}\text { Rojas et al. } \\
0.55 \pm 0.02\end{array}$} & \multirow{2}{*}{$\begin{array}{l}\text { Dos Santos et al. } \\
\qquad 0.53 \pm 0.04\end{array}$} \\
\hline & $\mathrm{CV}$ & & & & \\
\hline বे $\overline{\bar{\varepsilon}}$ & KV & $0.85 \pm 0.04^{*}$ & $0.79 \pm 0.02$ & $0.59 \pm 0.03$ & $0.60 \pm 0.04$ \\
\hline ఖँ & RV & $0.74 \pm 0.03^{*}$ & $0.70 \pm 0.03$ & $0.40 \pm 0.01$ & $0.44 \pm 0.04$ \\
\hline & EV & $2.48 \pm 0.08^{*}$ & $1.98 \pm 0.03$ & $1.40 \pm 0.03$ & $1.40 \pm 0.11$ \\
\hline \multirow{4}{*}{$\frac{\grave{0}}{\frac{0}{0}}$} & $\mathrm{CV}$ & $60.00 \pm 1.43^{*}$ & $58.57 \pm 3.59$ & $39.04 \pm 1.35$ & $37.86 \pm 2.57$ \\
\hline & KV & $42.50 \pm 2.06^{*}$ & $39.50 \pm 0.76$ & $29.50 \pm 1.50$ & $30.00 \pm 2.00$ \\
\hline & RV & $33.64 \pm 1.48^{*}$ & $31.82 \pm 1.39$ & $18.18 \pm 0.53$ & $20.00 \pm 1.66$ \\
\hline & EV & $47.69 \pm 1.54^{*}$ & $38.08 \pm 0.59$ & $26.92 \pm 0.63$ & $26.92 \pm 2.17$ \\
\hline \multicolumn{2}{|c|}{ Protein (g/dl) } & $11.83 \pm 0.09^{*}$ & $11.98 \pm 0.13$ & $11.51 \pm 0.24$ & $11.55 \pm 0.22$ \\
\hline \multicolumn{2}{|c|}{ Albumin (g/dl) } & $0.43 \pm 0.02$ & $0.42 \pm 0.05$ & $0.39 \pm 0.03$ & $036 \pm 0.02$ \\
\hline \multicolumn{2}{|c|}{ Globulin (g/dl) } & $11.40 \pm 0.09$ & $11.56 \pm 0.18$ & $11.12 \pm 0.26$ & $11.19 \pm 0.28$ \\
\hline \multicolumn{2}{|c|}{ A/G Ratio } & $0.038 \pm 0.002$ & $0.037 \pm 0.005$ & $0.037 \pm 0.005$ & $0.030 \pm 0.004$ \\
\hline \multirow{4}{*}{ 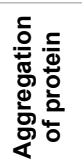 } & $4-8^{\circ} \mathrm{C}$ (15 days) & No & No & No & No \\
\hline & $35^{\circ} \mathrm{C}(15$ days $)$ & No & Mild & Moderate & Mild \\
\hline & $4-8^{\circ} \mathrm{C}$ (30 days) & No & No & Mild & No \\
\hline & $35^{\circ} \mathrm{C}$ (30 days) & No & Mild & High & Moderate \\
\hline \multicolumn{2}{|c|}{ Color } & Colorless & Yellow tinge & Bluish green & Dark yellow \\
\hline \multicolumn{2}{|c|}{ Toxicity in mice } & Non-toxic & Non-toxic & Non-toxic & Non-toxic \\
\hline \multicolumn{2}{|c|}{ Production time } & 1.5 days & 4.5 days & Not known & Not known \\
\hline
\end{tabular}

Table 5: Comparison of neutralizing potency and physio-chemical properties of polyvalent antivenom IgG recovered by different fractionation methods of hyperimmune equine plasma. The neutralization is expressed in $\mathrm{mg}$ venom neutralized per $\mathrm{mL}$ of antivenom. The results are expressed as mean value \pm S.D. ${ }^{*}<0.001$.

sulfate fractionation method. Besides, it also meets pharmacopeia requirements with respect to good neutralizing capacity, abnormal toxicity, and physicochemical characteristics (Table 5).

The antivenom and venom demonstrate characteristic and peculiar antigen antibody reaction patterns when allowed to diffuse freely in the gels or electrophoresed. The Gel diffusion electrophoretic pattern of serum purified by both caprylic acid and ammonium sulfate fractionation method demonstrated the identical patterns and hence provide fair correlation for the identical recoveries of different antibody fractions elicited against the potent antigenic venom fractions of all the four common Indian snake species. Under these standardized and validated conditions, a highly enriched polyvalent IgG protein fraction with good neutralizing ability and yield was obtained. When modified caprylic acid plasma fractionation method was compared with routinely used ammonium sulfate method, the results clearly indicated that the newly developed method was superior in terms of better yield, lower heterologous protein content, reduced albumin contamination, less production time, good neutralizing ability, no protein aggregates on storage and recovery of colorless finished product compared to yellowish tinged final product obtained with ammonium sulfate fractionation method. The formation of mild or no protein aggregates on long storage expected to induce less allergic reactions during the use $[6,32]$.

It is concluded from this study that the caprylic acid fractionation method is economical, simple, and much efficient, in terms of adequate neutralizing potency with lesser protein aggregate formation with recovery of a colorless product. However, before adapting this method on commercial scale, more extensive inter laboratory validation study is required so as to accept as an alternative method to the standard ammonium sulfate fractionation method.

\section{References}

1. Theakston RDG, Warrell DA (1991) Antivenoms: a list of hyperimmune sera currently available for the treatment of envenoming by bites and stings. Toxicon 29: $1419-1470$

2. Russel FE (1988) Snake venom immunology: historical and practical considerations. J Toxicol Toxin Rev 7: 1-82.

3. Raw YR, Guidolin HH, Kelen EM (1991) Antivenins in Brazil: Preparation. In Tu AT (eds.), Handbook of Natural Toxins. Vol 5, Reptile Venoms and Toxins. Marcel Dekker, New York, USA.

4. Dias WO, Izabel EM, Akiro FJ, Gondo HH, Roberto MJ, et al. (1989) Chromatographic purification of antivenoms and antitoxins. Mem Inst Butantan 51: 195-203.

5. Smith DC, Reddi KR, Laing G, Theakston RGD, Landon J (1992) An affinity purified ovine antivenom for the treatment of Vipera berus envenoming Toxicon 30: 865-871.

6. Rojas G, Jiménez JM, Gutiérrez JM (1994) Caprylic acid fractionation of hyperimmune horse plasma: description of a simple procedure for antivenom production. Toxicon 32: 351-363.

7. Deutsch HF (1967) Methods in Immunology and Immunochemisty. Academy 1e London.

8. Carter RJ, Boyd ND (1979) A comparison of methods for obtaining high yields of pure immunoglobulin from severely haemolysed plasma. J Immunol Methods 26: 213-32.

9. Pope CG, Healey M (1939) The preparation of diphtheria antitoxin in a state of high purity. Br J Exp Pathol 20: 213-216.

10. Corrigan P, Russell FE, Wainschel J Jr (1978) Clinical reactions to antivenin. In Toxins: Animal, plant, microbial. Rosenberg P (ed.), Oxford: Pergamon Press.

11. Su'l'herland SK, Lovering KE (1979) Antivenoms: use and adverse reactions over a 12 month period in Australia and Papua New Guinea. Med J Aust 2: 671-674.

12. Malasit $P$, Warrell DA, Chanthavanich $P$, Viravan $C$, Mongkolsapaya J, et al. (1986) Prediction, prevention, and mechanism of early (anaphylactic) antivenom reactions in victims of snake bites. Br Med J Clin Res Ed 292: 17-20.

13. Krifi MN, Ayeb ME, Dellagi K (1999) The improvement and standardization of antivenom production in developing countries: Comparing antivenom quality, therapeutical efficiency, and cost. J Venom Anim Toxins 5: 2-18.

14. Gutiérrez JM, Rojas E, Quesada L (2005) Pan-African poly specific antivenom produced by caprylic acid purification of horse lgG: an alternative to the antivenom crisis in Africa. Trans R Soc Trop Med Hyg 99: 468-475.

15. Vargas M, Segura A, Herrera M, Villalta M, Estrada R, et al. (2011) Preclinical evaluation of caprylic acid-fractionated IgG antivenom for the treatment of 
Citation: Sunil Kumar A, Rakshit P, Dilip Singh R, Ravi Kumar G (2016) Development of Modified Caprylic Acid Fractionation Method for the Enhanced Yield and Purity of Equine Polyvalent Antisnake Venom Immunoglobulins. J Bioprocess Biotech 6: 288. doi:10.4172/2155-9821.1000288

Page 6 of 6

Taipan (Oxyuranus scutellatus) envenoming in Papua New Guinea. PLoS Neg Trop Dis 5: e1144

16. Nudel BC, Perdoménico C, lácono R, Cascone O (2012) Optimization by factorial analysis of caprylic acid precipitation of non-immunoglobulins from hyperimmune equine plasma for antivenom preparation. Toxicon 59: 68-73.

17. Abdulla A, Casewell NR, Landon J (2014) Single-reagent one-step procedures for the purification of ovine IgG, $F\left(a b^{\prime}\right) 2$ and Fab antivenoms by caprylic acid. $J$ Immunol Methods 402: 15-22.

18. Manual for Production and Quality Control of Hyper Immune Antisera (1990) Central Research Institute, Kasauli, Himachal Pradesh, India.

19. World Health Organization (2010) Guidelines for the production, control and regulation of antivenom immunoglobulins.

20. Indian Pharmacopeias (2014) Antisera.

21. Dos-Santos MC, D'imperio-Lima MR, Furtado GC, Colletto GMDD, Kipnis TL, et al. (1989) Purification of $F\left(a b^{\prime}\right) 2$ anti- snake venom by caprylic acid: a fast method for obtaining lgG fragments with high neutralization activity, purity and yield. Toxicon 27: 297-303.

22. Schosinsky K, Vargas M, Vinocour G (1983) Manual de Técnicas de Laboratorio. Química Clínica. Universidad de Costa Rica, San José.

23. Minton SA (1971) Snake venoms and envenomation. Marcel Dekker Inc., New York, USA.
24. Gitter S, Chaja MP, Boss JH, Ella L, Jadwiga R, et al. (1962) Studies on the snake venoms of the near East: Walterinnesia aegyptia and Pseudocerastes Field. Am J Trop Med Hyg 11: 861-868.

25. Russell FE (1980) Snake venom poisoning. Philadelphia: JB Lippincott Comp.

26. de Silva HA, Ryan NM, de Silva HJ (2015) Adverse reactions to snake antivenom, and their prevention and treatment. $\mathrm{Br} \mathrm{J}$ Clin Pharmacol 81 446-452.

27. Rafael OP, Segurac A, Herrerac M, Angulo Y, León G, et al. (2012) Comparative study of the efficacy and safety of two polyvalent, caprylic acid fractionated [IgG and $F\left(a b^{\prime}\right) 2$ ] antivenoms, in Bothrops asper bites in Colombia. Toxicon 59: 344-355.

28. Karliner JS, Belaval GS (1965) Incidence of reactions following administration of antirabies serum. JAMA 193: 359-362.

29. King AA, Turner GS (1993) Rabies: a review. J Comp Pathol 108: 1-39.

30. Pope CG, Stevens MF (1951) The action of proteolytic enzymes on the antitoxins and proteins in immune sera. III. Further studies on enzyme systems which split the antitoxin molecule. Brit J Exp Path 32: 314-324.

31. Steinbuch M, Audran R (1969) The isolation of IgG from mammalian sera with the aid of caprylic acid. Arch Biochem Biophys 134: 279-284.

32. Zolfagharian H, Dounighi MN (2013) Progress and improvement of the manufacturing process of snake antivenom. Arch Razi Inst 68: 1-10. 